\title{
Evaluation of Corneal Reflectance in Sjögren's Syndrome Dry Eye
}

\author{
Sandro Sbordone ${ }^{1}$, Adele Ragucci ${ }^{1}$, Gennarfrancesco Iaccarino ${ }^{1}$, Domenico de Robertis ${ }^{1}$, Giovan Battista Scazzi ${ }^{1}$ \\ $\&$ Michele Lanza ${ }^{1}$ \\ ${ }^{1}$ Multidisciplinary Department of Medical, Surgical and Dental Specialites, Università della Campania Luigi \\ Vanvitelli, Napoli, Italy \\ Correspondence: Michele Lanza, Multidisciplinary Department of Medical, Surgical and Dental Specialites, \\ Università della Campania Luigi Vanvitelli, Napoli, Italy. E-mail: mic.lanza@gmail.com
}

Received: October 5, 2020; Accepted: October 30, 2020; Published: November 2, 2020

The authors report no conflicts of interest. Grant/funding: This project did not receive external funding.

\begin{abstract}
Introduction: To measure corneal layers' light reflectance (LR) in eyes affected by dry eye disease caused by Sjögren's syndrome (SSDE) with corneal confocal microscopy (IVCM) and to study the correlations with tear film tests.

Materials and Methods: Thirty-six patients affected by SSDE and 36 healthy subjects (HS) were enrolled in this retrospective study, participants of both groups were age and sex matched. Each study participants had a complete eye visit and break up time (BUT), Schirmer test, with and without stimulation, at the end of the visit an IVCM scan was performed. LR measured by IVCM at Bowman membrane (BM) level and at $50 \mu \mathrm{m}$, at $100 \mu \mathrm{m}$ and at $200 \mu \mathrm{m}$ deeper was compared in the two groups of participants. The correlations between LR measurements and tear film test results were investigated.
\end{abstract}

Results: In SSDE eyes, LR was significantly higher $(p<0.001)$ in SSDE patients at BM level $(+14.43 \pm 3.27 \mathrm{LRU})$ and also in the other levels evaluated, compared with HP. Good correlations were observed between LR values at BM and Schirmer test ones with $(r=-0.82)$ and without $(r=-0.81)$ stimulation and BUT $(r=0.80)$ in SSDE eyes. Correlations values were Adecreasing the deeper corneal layers.

Conclusion: Even if need to be verified in further studies with a larger population, results obtained in this study suggest that IVCM could be an interesting and effective tool in evaluating the SSDE patients and it could be adopted by physicians' community because it seems very promising.

Keywords: corneal confocal microscopy, early diagnosis, Sjögren's Syndrome, corneal surface, Schirmer test, break up time

\section{Introduction}

Dry eye is an ocular surface disease that could be frequently observed in in the adult population affected by Sjögren's syndrome [1-6]. Main features of this chronic autoimmune disease, indeed, are inflammation and reduction of secretory ability of the exocrine glands [1]. Primary Sjögren syndrome is defined as primary if there are no associations with other autoimmune diseases, when these ones are detected, such as systemic lupus erythematous or rheumatoid arthritis, it is defined as secondary one [1]. Ocular surface alterations are related to the action of lymphocytes and the production of inflammatory cytokines leading to functional damage of the lacrimal functional unit [7]. If these alterations are not accurately managed, the clinical stage could evolve in a Sjögren syndrome dry eye (SSDE) [2-6]. The reduction of secretion of aqueous elements of tears has been considered the main mechanism of SSDE insurgence [5] but, recently, it has been recognized that the pathogenesis of this disease is more complex and involve many factors such as osmolality tears variation, corneal innervation modifications, corneal sensitivity alterations and the presence of inflammation [5-8].

SSDE management showed the limits of devices traditionally used for morphological and functional evaluation of the eyes $[8,9]$. This is the reason because new instruments and tools are introduced in the management of SSDE eyes. Among these, physicians largely adopted in vivo confocal microscopy (IVCM) to detect corneal alterations in patients affected by dry eye related or not to Sjögren syndrome [10-12]. Features most frequently analyzed with IVCM were integrity of ocular surface, corneal cells morphology and corneal innervation plexus [13-22], 
providing qualitative evaluations. IVCM is able to provide a quantitative parameter such as the light reflectance (LR), verified to be reliable in staging corneal inflammation in different diseases [23-26].

To have new tools able to make earlier diagnosis of this SSDE and to detect new signs of this disease during follow up could help physicians in the care of this patients.

This study is aiming to evaluate characteristics and usefulness of LR measured by IVCM in SSDE patients in order to improve tools available for physicians both to earlier detect this disease and both to improve the quality of life of these patients. LR has been chosen because it is a quantitative, continuous variable that could be used to evaluate the changes in inflammation levels of these eyes during follow up or to help in detecting SSDE eyes in earlier stage.

\section{Methods}

A total of 36 patients ( 35 women and 1 man) with a mean age of $47.35 \pm 10.51$ years (range from 26 to 71 years), with SSDE and 36 healthy subjects (HS), age and sex matched were included in this retrospective study. SSDE patients were referring at Ophthalmology Unit of Università della Campania Luigi Vanvitelli (Napoli, Italy) as part of their overall rheumatology management. 2012 American-European Classification Criteria were used to make diagnosis of primary Sjogren's syndrome [27, 28]. The EULAR Sjogren's Syndrome Disease Activity Index was used to measure the disease activity. HS subjects included in the study were selected among them enrolled to have refractive surgery at same Ophthalmology Unit.

Patients and HS with a history of ocular surgery, wearing contact lenses less than 1 month before enrollment were excluded by this study. Moreover, other exclusion criteria were corneal dystrophies and inflammations, ocular or general infection, diabetes mellitus, sarcoidosis and lymphoma. Participants of both groups were screened with a complete eye visit moreover lacrimal gland functional test performed following indications of International Dry Eye Workshop 2007 such as Schirmer test with (ST I) and without (ST II) stimulation, break up time (BUT) according to guidelines [25], and IVCM evaluation at the end, after 20 minutes of the tear tests in order to perform scans through a stable and clear tear film.

Confoscan 3 (Nidek technologies, Vigonza, Italy) was used for every subject included in the study. The images were acquired by previously described technique [10-12]. Scans performed in this study were acquired full automatic setting, with $2 \mu \mathrm{m}$ of gap between two consecutive imagines. For every scan was chosen a fixed light intensity of 160, aiming to obtain the best endothelium image quality. The reflex of the light at the focal plane was acquired by a charge-coupled device (CCD) camera with a standard 40X object lens. This device has an interestin tool that is able to display the intra-corneal layer and to provide the measurement level in micrometers on the antero-posterior scans of the corneas: the Z-scan. Using the Z scan tool, is has been possible to detect the level of LR, measured as LR units (LRU), on the y-axis for each corneal image acquired during the scan [29-31]. Well trained physicians (GBS and GI) carefully evaluated scans detecting the LRU values at and the Bowman membrane, defined as the first stromal layer after the sub-basal epithelium, and the ones detected at $50 \mu \mathrm{m}, 100 \mu \mathrm{m}$ and $200 \mu \mathrm{m}$ deeper from it. Only good quality scans were included in the study and LRU values used for statistical evaluation.

\section{Statistical Analysis}

Kolmogorov-Smirnov test was run to check the normal distribution of data of this study. For ones not meeting normality, appropriate non parametric tests were applied to study differences and correlations. In particular, since the two groups were matched according to age and gender, we considered these as unpaired data. The two groups were compared with one-way factorial ANOVA for each parameter. Correlations between lacrimal functional tests such as BUT, ST I and ST II with the quantitative parameter provided by IVCM, such as LR were evaluated with the Spearman's rank order correlation method. For all tests the level of significance was fixed at $p<0.05$. All analyses were performed using SPSS software (IBM Corp. Armonk, New York) version 18.0.

All subjects gave their informed consent for using their data before starting every visits. The study was conducted in accordance with the Declaration of Helsinki, and the protocol was approved by the Ethics Committee of Università della Campania Luigi Vanvitelli as retrospective study

\section{Results}

Table 1 shows the mean values of age and tear tests performed in SSDE and HS. Significant differences were observed in BUT, Schirmer test I and II values. 
Table 1. Means and standard deviations of age, lacrimal gland functions values measured both in SSDE and both in HS eyes

\begin{tabular}{|c|c|c|c|c|c|c|c|}
\hline \multirow[b]{3}{*}{ Age (vears) } & \multicolumn{3}{|l|}{ SSDE } & \multicolumn{3}{|c|}{ Healthy subjects } & \multirow[t]{2}{*}{ Mann-Whitney U tes } \\
\hline & Means & \pm & SD & mean & \pm & SD & \\
\hline & 47.35 & \pm & 10.51 & 49.12 & \pm & 11.37 & $\mathrm{p}=0.6$ \\
\hline Schirmer test I (mm) & 3.43 & \pm & 2.12 & 16.67 & \pm & 4.36 & $\mathrm{p}<0.001$ \\
\hline Schirmer test II $(\mathrm{mm})$ & 2.31 & \pm & 1.64 & 12.43 & \pm & 3.58 & $\mathrm{p}<0.001$ \\
\hline BUT (seconds) & 4.21 & \pm & 2.32 & 11.43 & \pm & 1.52 & $\mathrm{p}<0.001$ \\
\hline
\end{tabular}

SSDE: Sjogren's syndrome dry eye; BUT: break up time; SD: standard deviation

LR values comparison between SSDE patients and HS showed a statistically significant underestimation $(\mathrm{p}<0.001)$ in every layer analyzed (Table 2); the differences were higher in the most superficial stromal layers whereas they were lower in deeper ones analyzed.

Table 2. LR values measured both in (SSDE) and HS at Bowman membrane (BM) level and $50 \mu \mathrm{m}, 100 \mu \mathrm{m}$ and $200 \mu \mathrm{m}$ deeper

\begin{tabular}{llllllll}
\hline & \multicolumn{9}{c}{ SSDE } & \multicolumn{5}{c}{ Healthy subjects } & Mann-Whitney U test \\
\cline { 2 - 6 } & Mean & \pm & SD & mean & \pm & SD & \\
\cline { 2 - 6 } & 35.07 & \pm & 6.41 & 20.64 & \pm & 1.34 & $\mathrm{p}<0.001$ \\
$50 \mu \mathrm{m}$ & 30.04 & \pm & 4.24 & 18.67 & \pm & 0.92 & $\mathrm{p}<0.001$ \\
$100 \mu \mathrm{m}$ & 27.64 & \pm & 4.34 & 18.52 & \pm & 1.05 & $\mathrm{p}<0.001$ \\
$200 \mu \mathrm{m}$ & 26.43 & \pm & 5.08 & 17.08 & \pm & 0.98 & $\mathrm{p}<0.001$ \\
\hline
\end{tabular}

In SSDE patients the higher reflectivity in all layers showed a significant inverse correlation with ST I, ST II and BUT $(\mathrm{p}<0.001)$. These correlations appeared to be weaker in the deeper stromal layers (Table 3 ).

Table 3. Correlations evaluated among Schirmer test 1(ST I) Schirmer test 2 (ST II), break up time (BUT) values and LRU values observed at Bowman layer (BM) and $50 \mu \mathrm{m}, 100 \mu \mathrm{m}$ and $200 \mu \mathrm{m}$ deeper in SSDE eyes

\begin{tabular}{llllll}
\hline \multicolumn{5}{c}{ Correlations in SSDE } \\
\hline \multirow{5}{*}{ ST I } & Spearman's rho & BM & $50 \mu \mathrm{m}$ & $100 \mu \mathrm{m}$ & $200 \mu \mathrm{m}$ \\
& Sig. (2-tailed) & -0.824 & -0.621 & -0.554 & -0.501 \\
& $\mathrm{~N}$ & $\mathrm{p}<0.001$ & $\mathrm{p}<0.001$ & $\mathrm{p}<0.001$ & $\mathrm{p}<0.001$ \\
& Spearman's rho & -0.808 & -0.597 & -0.512 & 36 \\
\hline \multirow{3}{*}{ ST II } & Sig. (2-tailed) & $\mathrm{p}<0.001$ & $\mathrm{p}<0.001$ & $\mathrm{p}<0.001$ & $\mathrm{p}<0.478$ \\
& $\mathrm{~N}$ & 36 & 36 & 36 & 36 \\
& Spearman's rho & -0.798 & -0.574 & -0.487 & -0.462 \\
& BUT & $\mathrm{p}<0.001$ & $\mathrm{p}<0.001$ & $\mathrm{p}<0.001$ & $\mathrm{p}<0.001$ \\
& Sig. (2-tailed) & 36 & 36 & 36 & 36 \\
\hline
\end{tabular}

As it is possible to observe in Table 4, the relations among the LR values measured at every layers and Schirmer test I, II and BUT evaluations didn't show significant differences in the different age range considered. 
Table 4. Correlations analysed among LR values measure at Bowman membrane (BM) and $50 \mu \mathrm{m}(50), 100 \mu \mathrm{m}$ (100) and $200 \mu \mathrm{m}$ (200) deeper and Schirmer test I and II and break up time (BUT) in Sjogren Syndrome Dry Eyes (SSDE) patients divided in 3 groups of age

\begin{tabular}{|c|c|c|c|c|c|c|}
\hline \multicolumn{2}{|c|}{ SSDE age range $24-40$} & & BM & 50 & 100 & 200 \\
\hline \multirow[t]{9}{*}{ Spearman's rho } & SCHIRMER I & Spearman's rho & -0.7885 & -0.5214 & -0.7286 & -0.6231 \\
\hline & & Sig. (2-tailed) & $<0.01$ & $<0.01$ & $<0.01$ & $<0.05$ \\
\hline & & $\mathrm{N}$ & 8 & 8 & 8 & 8 \\
\hline & SCHIRMER II & Spearman's rho & -0.7089 & -0.5306 & -0.6348 & -0.5469 \\
\hline & & Sig. (2-tailed) & $<0.05$ & 0.014 & $<0.05$ & 0.081 \\
\hline & & $\mathrm{N}$ & 8 & 8 & 8 & 8 \\
\hline & BUT & Spearman's rho & -0.7584 & -0.5473 & -0.6241 & -0.5604 \\
\hline & & Sig. (2-tailed) & $<0.01$ & $<0.01$ & $<0.05$ & 0.062 \\
\hline & & $\mathrm{N}$ & 8 & 8 & 8 & 8 \\
\hline \multicolumn{7}{|c|}{ SSDE age range 41-45 } \\
\hline \multirow[t]{9}{*}{ Spearman's rho } & SCHIRMER I & Spearman's rho & -0.8627 & -0.7333 & -0.6518 & -0.2687 \\
\hline & & Sig. (2-tailed) & $<0.01$ & $<0.01$ & $<0.01$ & 0.154 \\
\hline & & $\mathrm{N}$ & 18 & 18 & 18 & 18 \\
\hline & SCHIRMER II & Spearman's rho & -0.8748 & -0.7148 & -0.6447 & -0.3147 \\
\hline & & Sig. (2-tailed) & $<0.01$ & $<0.01$ & $<0.01$ & 0.149 \\
\hline & & $\mathrm{N}$ & 18 & 18 & 18 & 18 \\
\hline & BUT & Spearman's rho & -0.8689 & -0.6841 & -0.5204 & -0.3584 \\
\hline & & Sig. (2-tailed) & $<0.01$ & $<0.01$ & $<0.05$ & 0.077 \\
\hline & & $\mathrm{N}$ & 18 & 18 & 18 & 18 \\
\hline \multicolumn{7}{|c|}{ SSDE age range 56-72 } \\
\hline \multirow{9}{*}{ Spearman's rho } & SCHIRMER I & Spearman's rho & -0.8408 & -0.7145 & -0.3649 & -0.5347 \\
\hline & & Sig. (2-tailed) & $<0.01$ & $<0.01$ & 0.137 & $<0.05$ \\
\hline & & $\mathrm{N}$ & 10 & 10 & 10 & 10 \\
\hline & SCHIRMER II & Spearman's rho & -0.9214 & -0.7261 & -0.5062 & -0.6327 \\
\hline & & Sig. (2-tailed) & $<0.01$ & $<0.01$ & $<0.05$ & $<0.01$ \\
\hline & & $\mathrm{N}$ & 10 & 10 & 10 & 7 \\
\hline & BUT & Spearman's rho & -0.6784 & -0.4892 & -0.3451 & -0.6419 \\
\hline & & Sig. (2-tailed) & $<0.01$ & $<0.05$ & 0.196 & $<0.05$ \\
\hline & & $\mathrm{N}$ & 10 & 10 & 10 & 10 \\
\hline
\end{tabular}

\section{Discussion}

Dry eye is one of the main sign of a complex autoimmune syndrome such as the Sjogren's one [1]. The improvements in the technology today available let the physicians to consider new roads to improve the overall management of these patients, overcoming the limitations of standard diagnostic devices [6,9]. The early symptoms and signs of SSDE are very common and could be easily misdiagnosed by physicians [6,9]. It is possible to observe the same difficulties in evaluating the improvements in many symptoms communicated by patients [6]. Measurable and reliable parameters are, indeed, more useful in diagnosis and management of SSDE patients. IVCM has been used in this study because of its potential usefulness, largely proven in different studies about evaluation of corneal and conjunctival diseases [20-22]. Particularly, IVCM has been applied in dry eye studies because it has been shown to be able to detect morphological anomalies in corneal superficial layer in patients affected by this disease [20-22]. The most important alterations detectable with this device are descriptive ones, allowing physicians to observe a corneal morphology modified by different kind of diseases [20-22]. Quantification of corneal inflammation could be an interesting tool because this process has been recognized to be involved in SSDE eyes [5-9], this is the reason because LR provided by IVCM has been used in this study. LR measurements have been defined a reliable tool, able to evaluate early corneal inflammation following cataract surgery (phacoemulsification), herpetic stromal keratitis lamellar keratoplasty, or corneal haze [20-32]. Values of LR observed in this study are very lower respect to the ones previously reported but this could due to the very lower inflammation levels that characterize SSDE patients compared to the conditions previously listed [20-32]. Main advantages of IVCM are safety and quickness of the examination moreover, it is a non-invasive device because the lens never touch the cornea [10-12]. The technique used could be also a limit of this study because 
IVCM acquisitions could be biased by several artifacts due to corneal alterations in measuring LR. Moreover, sometime could be difficult to scan the central cornea, this is the reason because a semi-automatic acquisition settling mode has been chosen in this study. The physician (ML) that performed every scan is a well-trained one and after individuating the sharper endothelial picture, the following scans were acquired without any other interaction with the operator. In this study, SSDE eyes showed significant higher values of LR compared to HP included in the study (age and sex matched). Thus, these parameters could be used to distinguish SSDE from healthy eyes. Another important finding of this study is the presence of correlations between the LR values measured in the corneal layer scanned and the lachrymal function tests. This suggests that physicians could obtain a reliable, objective and quantitative measurements of corneal inflammation and this is particularly important in SSDE patients because it is not easy to correctly evaluate signs and symptoms using the most currently used devices [6]. Patients often describe the sensations related to their eye conditions as "sandy" or "gritty" but the physicians have often difficulties in detecting related signs using the slit lamp ${ }^{6}$ and this make very hard to manage these patients and their therapy. LR provided by IVCM could improve the ability of overall management of Sjögren's syndrome patients, other kind of dry eye related diseases and could open new roads to research prospective. To make this device useful, it is important to apply a standardized approach to every scan, in order to avoid multiple interpretations, as it is possible to observe in the evaluations of sub-basal nerve plexus [31]. Tepelus et al. [33] published an interesting article that provided information about corneal innervation density in Sjogren and not Sjogren eyes but didn't analyze light reflectivity of them. They highlighted the importance of a new device such as the confocal microscopy in the routine evaluation of SSDE even if they evaluated a different device compared to the one used in the current study [33]. Data observed in this study suggest that IVCM could be an interesting tool in evaluating the corneal layers of patients affected by SSDE because it could improve the knowledge of the relations between functional and morphological alterations in these eyes. Further studies are needed to confirm these results and to improve the interpretation of LR values in relations to subjective symptoms and the results of lacrimal functional tests. To build a reliable database of healthy, borderline and diseased LR could help to earlier identify first signs of SSDE manifestations and to better evaluate these eyes during follow up, properly modulating their therapy.

\section{References}

[1] Peri, Y., Agmon-Levin, N., Theodor, E., \& Shoenfeld, Y. (2012). Sjögren's syndrome, the old and the new. Best Pract Res Clin Rheumatol, 26, 105-117. https://doi.org/10.1016/j.berh.2012.01.012

[2] Afonso, A. A., Sobrin, L., Monroy, D. C. et al. (1999). Tear fluid gelatinase B activity correlates with IL-1a concentration and fluorescein clearance in ocular rosacea. Invest Ophthalmol Vis Sci., 40, 2506-2512.

[3] Pflugfelder, S. C., Jones, D., Ji, Z. et al. (1999). Altered cytokine balance in the tear fluid and conjunctiva of patients with Sjogren's syndrome keratoconjunctivitis sicca. Curr Eye Res., 19, 201-211.

[4] Solomon, A., Dursun, D., Liu Z. et al. Pro- and anti-inflammatory forms of interleukin-1 in the tear fluid and conjunctiva of patients with dry-eye disease. Invest Ophthalmol Vis Sci. 2001;42, 2283-2292.

[5] The definition and classification of dry eye disease: report of the Definition and Classification Subcommittee of the International Dry Eye Workshop (2007). Ocul Surf, 5, 75-92. https://doi.org/10.1016/s1542-0124(12)70081-2

[6] Tincani, A., Andreoli, L., Cavazzana, I. et al. (2013). Novel aspects of Sjögren's syndrome in 2012. BMC Med., 4, 93. https://doi.org/10.1186/1741-7015-11-93

[7] Stern, M. E., Beuerman, R. W., Fox, R. I. et al. (1998). The pathology of dry eye: the interaction between the ocular surface and lacrimal glands. Cornea, 17, 584-589.

[8] Mathers, W. D. (1998). Ocular evaporation in meibomian gland dysfunction and dry eye. Ophthalmology., 100, 347-351.

[9] Villani, E., Galimberti, D., Viola, F. et al. (2007).The cornea in Sjogren's syndrome: an in vivo confocal study. Invest Ophthalmol Vis Sci., 48, 2017-2022.

[10] Tuisku, I. S., Konttinen, Y. T., Konttinen, L. M. et al. (2008). Alterations in corneal sensitivity and nerve morphology in patients with primary Sjögren's syndrome. Exp Eye Res., 86, 879-885. https://doi.org/10.1016/j.exer.2008.03.002

[11] Villani, E., Magnani, F., Viola, F. et al. (2013). In vivo confocal evaluation of the ocular surface morpho-functional unit in dry eye. Optom Vis Sci., 90, 576-586. https://doi.org/10.1097/OPX.0b013e318294c184 
[12] Labbé, A., Liang, Q., Wang, Z. et al. (2013). Corneal nerve structure and function in patients with non-sjogren dry eye: clinical correlations. Invest Ophthalmol Vis Sci. 54,5144-5150. https://doi.org/10.1167/iovs.13-12370

[13] Lanza, M., Iaccarino, S., Varricchi, G., D'Errico, T., Gironi, Carnevale U. A., Bifani, M. (2017). Corneal confocal microscopy alterations in Sjögren's syndrome dry eye. Acta Ophthalmol., 95, e366-e372. https://doi.org/10.1111/aos.13194

[14] Tuominen, I. S., Konttinen, Y. T., Vesaluoma, M. H. et al. (2003). Corneal innervation and morphology in primary Sjögren's syndrome. Invest Ophthalmol Vis Sci., 44, 2545-2549. https://doi.org/10.1167/iovs.02-1260

[15] Benítez, del Castillo, J. M., Wasfy, M. A., Fernandez, C. et al. (2004). An in vivo confocal masked study on corneal epithelium and subbasal nerves in patients with dry eye. Invest Ophthalmol Vis Sci., 45, 3030-3035. https://doi.org/10.1167/iovs.04-0251

[16] Zhang, M., Chen, J., Luo, L. et al. (2005). Altered corneal nerves in aqueous tear deficiency viewed by in vivo confocal microscopy. Cornea., 24, 818-824. https://doi.org/10.1097/01.ico.0000154402.01710.95

[17] Benítez, del Castillo, J. M., Acosta, M. C., Wassfi, M. A. et al. (2007). Relation between corneal innervation with confocal microscopy and corneal sensitivity with noncontact esthesiometry in patients with dry eye. Invest Ophthalmol Vis Sci., 48, 173-181. https://doi.org/10.1167/iovs.06-0127

[18] Villani E., Galimberti D., Viola F. et al. (2008). Corneal involvement in rheumatoid arthritis: an in vivo confocal study. Invest Ophthalmol Vis Sci., 49, 560-564. https://doi.org/10.1167/iovs.07-0893

[19] Lin, H., Li, W., Dong, N. et al. (2010). Changes in corneal epithelial layer inflammatory cells in aqueous tear-deficient dry eye. Invest Ophthalmol Vis Sci., 51, 122-128. https://doi.org/10.1167/iovs.09-3629

[20] Levy O., Labbé A., Borderie V., Hamiche T., Dupas B., Laroche L., Baudouin C., \& Bouheraoua N. (2017). Increased corneal sub-basal nerve density in patients with Sjögren syndrome treated with topical cyclosporine A. Clin Exp Ophthalmol., 45, 455-463. https://doi.org/10.1111/ceo.12898.

[21] Lee, O. L., Tepelus, T. C., Huang, J., Irvine, A. G., Irvine, C., Chiu, G. B., \& Sadda, S. R. (2018). Evaluation of the corneal epithelium in non-Sjögren's and Sjögren's dry eyes: an in vivo confocal $\begin{array}{lllllll}\text { microscopy study using HRT III RCM. BMC Ophthalmol, } 18, & 309 .\end{array}$ https://doi.org/10.1186/s12886-018-0971-3

[22] Cardigos, J., Barcelos, F., Carvalho, H., Hipólito, D., Crisóstomo, S., Vaz-Patto, J., \& Alves, N. (2019). Tear Meniscus and Corneal Sub-basal Nerve Plexus Assessment in Primary Sjögren Syndrome and Sicca Syndrome Patients. Cornea., 38, 221-228. https://doi.org/10.1097/ICO.0000000000001800.

[23] Marchini, G., Mastropasqua, L., Pedrotti, E., Nubile, M., Ciancaglini, M., \& Sbabo, A. (2006). Deep lamellar keratoplasty by intracorneal dissection: a prospective clinical and confocal microscopic study. Ophthalmology, 113, 1289-1300. https://doi.org/10.1016/j.ophtha.2006.01.071

[24] Morishige, N., Takahashi, N., Chikamoto, N., \& Nishida, T. (2009). Quantitative evaluation of corneal epithelial oedema by confocal microscopy. Clin Experiment Ophthalmol, 37, 249-253. https://doi.org/10.1111/j.1442-9071.2009.02020.x

[25] Hillenaar, T., van Cleynenbreugel, H., Verjans, G. M., Wubbels, R. J., \& Remeijer, L. (2012). Monitoring the inflammatory process in herpetic stromal keratitis: the role of in vivo confocal microscopy. Ophthalmology, 119, 102-1110. https://doi.org/10.1016/j.ophtha.2011.12.002

[26] Schiano-Lomoriello, D., Colabelli-Gisoldi, R. A., Nubile, M. et al. (2014). Descemetic and Predescemetic DALK in Keratoconus Patients: A Clinical and Confocal Perspective Study. BioMed Res Int., 123-156 https://doi.org/10.1155/2014/123156

[27] Shiboski, S. C., Shiboski, C. H., Criswell, L. et al. (2012). American College of Rheumatology classification criteria for Sjögren's syndrome: a data-driven, expert consensus approach in the Sjögren's International Collaborative Clinical Alliance cohort. Arthritis Care Res (Hoboken)., 64, 475-487. https://doi.org/10.1002/acr.21591

[28] Methodologies to diagnose and monitor dry eye disease: report of the Diagnostic Methodology Subcommittee of the International Dry Eye Work Shop (2007). Ocul Surf, 5, 108-152. https://doi.org/10.1016/s1542-0124(12)70083-6

[29] McLaren, J. W., Nau, C. B., Patel, S. V. et al. (2017). Measuring corneal thickness with the ConfoScan 4 
and z-ring adapter. Eye and Contact Lens, 33, 185-190. https://doi.org/10.1097/ICL.0b013e31802b3114

[30] McLaren, J. W., Bourne, W. M., \& Patel, S. V. (2010). Standardization of corneal haze measurement in confocal microscopy. Invest Ophthalmol Vis Sci., 51, 5610-5616. https://doi.org/10.1167/iovs.10-5614

[31] Labbe A., Alalwani H., Van Went C. et al. (2012). The relationship between subbasal nerve morphology and corneal sensation in ocular surface disease. Invest Ophthalmol Vis Sci., 53, 4926-4931. https://doi.org/10.1167/iovs.11-8708

[32] Mastropasqua, L., \& Nubile, M. (2002). Confocal Microscopy of the Cornea. Thorofare(NJ),1, 127-131

[33] Tepelus, T. C., Chiu, G. B., Huang, J. et al. (2017). Correlation between corneal innervation and inflammation evaluated with confocal microscopy and symptomatology in patients with dry eye syndromes:
a preliminary
study.
Graefes Arch
Clin Exp
Ophthalmol,
$255, \quad 1771-1778$.

https://doi.org/10.1007/s00417-017-3680-3

\section{Copyrights}

Copyright for this article is retained by the author(s), with first publication rights granted to the journal.

This is an open-access article distributed under the terms and conditions of the Creative Commons Attribution license (http://creativecommons.org/licenses/by/4.0/). 